\title{
Prevalence and epidemiological findings of MDR (Multi-Drug Resistant) Typhoid bacillus in district Swat KPK, Pakistan
}

\begin{abstract}
Typhoid fever remains an imperative public health matter in many developing countries and prevails in areas with poor hygiene, which aids its spread and diligence in the human population. During this study the prevalence of typhoid fever was recorded different with respect to season, months, age and gender among patients visiting the different hospitals and health care centers of selected area. The clinical data collected from the patients were recorded and designated based on age, gender, marital status, monthly occurrence and seasonal occurrence. During year 2012, 2252 were diagnosed for typhoid out of which 346 were positive for typhoid. The occurrence ratio observed high in age group $45-60(64.16 \%)$ while lowest in $0-15(0.58 \%)$ while gender wise prevalence shows male predominance among all cases (162 female and 184 male). Out of 346 patients, $272(78.6 \%)$ patients were married and $74(21.4 \%)$, monthly occurrence was recorded higher in June, July and August $(11.85 \%, 16.90 \%, 17.34 \%)$ respectively. The seasonal prevalence was high in summer $(55.79 \%)$ while it gradually decreases in spring $(18.20 \%)$, autumn $(17.63 \%)$ and winter $(8.38 \%)$. This study was conducted for the first time in district swat to find out the prevalence rate, risk factors associated with typhoid occurrence, to suggest prophylactic measures to local community and give recommendations to Public Health Department to ensure the prevention and control of this fatal disease.
\end{abstract}

Keywords: clinical findings, epidemiology, typhoid fever, district swat
Volume 4 Issue 5 - 2017

\author{
Ali Khan A,' Ahmad, ${ }^{2}$ ljaz-ul Haq, ${ }^{2}$ Khan $S,{ }^{2}$ \\ Khan A,' Ghani $S^{3}$ \\ 'Department of Zoology, Abdul Wali Khan University, Pakistan \\ 2Department of Zoology, University of Malakand, Pakistan \\ ${ }^{3}$ Department of Biotechnology, Islamic International University, \\ Pakistan
}

Correspondence: Asar Khan, Department of Zoology, Abdul Wali Khan University, Mardan KPK, Pakistan, Tel: +92-340-9427906; Email asar1056@gmail.com

Received: August 04, 2017 | Published: October 16, 2017

\section{Introduction}

Typhoid is a severe, contagious and life-threatening disease associated with fever that is most often caused by the typhoid bacillus, Salmonella enterica, serovar Typhus. Typhoid fever is transmitted by ingestion of food, including dairy products, or water contaminated by excreta from patients or chronic by infected persons. It mostly affects school-age children. In adults and older people, typhoid is less frequent but much more severe. It has various names, such as gastric fever, abdominal typhus, infantile remittent fever, slow fever, nervous fever, and pathogenic fever. However, Salmonella Typhus and Salmonella Paratyphoid do not have animal reservoir, therefore infection can be happened by eating the improperly handled food by infected individuals. ${ }^{1}$ Enteric fever (typhoid or paratyphoid fever) is a potentially fatal systemic infection. Typhoid fever is caused by Salmonella enterica, serovar Typhus (S. Typhi) and paratyphoid fever is caused by Salmonella enterica, serovar Paratyphoid (S. Paratyphi) A, B, or C. These organisms cause disease specifically in humans. Paratyphoid fever is usual "typhoid" was given by Louisin1829, as a derivative from typhus in brief, Salmonella is facultative anaerobe, and gram negative flagellated rod-shaped Bacteria. ${ }^{2}$ It is among the most commonly isolated food borne pathogens associated with fresh fruits and vegetables. In recent years, the incidence of fresh fruits and vegetables has increased and become a great concern in industrialized countries. Out breaks of salmonellas is have been linked to a wide variety of fresh fruits and vegetables including apple, cantaloupe, alfalfa sprout, mango, lettuce, cilantro, un-pasteurized orange juice, tomato, melon, celery and parsley. ${ }^{3}$

An estimated 21.6 million new cases of typhoid fever with about 216, 510 deaths occurred globally in 2000. Paratyphoid fever caused about 5.4 million illnesses in the same year. ${ }^{4}$ Most cases occur in the middle-income and low-income countries where sanitation is poor and water supply is in adequate. ${ }^{5}$ Endemic enteric fever is common in the Indian subcontinent, South-East and Far East Asia, Africa, Central and South America, and the Mediterranean region. ${ }^{6}$ Typhoid fever was reported to be endemic in Far East Asia, Middle East, Central and South America. It remains a serious problem in Zimbabwe. ${ }^{7}$ Various reports on pathogenesis of typhoid fever have been made and molecular pathogenesis of Salmonella enteric serotype typhimurium was also studied by Zhang et al. ${ }^{8}$

Typhoid fever is characterized by high fever, paradoxical bradycardia, and rose-colored rash out of which the most common complaints were headache, abdominal pain and diarrhea. Patient suffering from typhoid fever may develop the symptoms like digestive hemorrhages, ileocaecal perforation, encephalitides, myocarditides, enter bacterial super infections, ${ }^{9}$ ilea perforation, ${ }^{10}$ pancreatitis, acute pancreatitis, ${ }^{11}$ intestinal perforation, ${ }^{12}$ bowel perforation, infarction abscess,${ }^{13}$ hepatic dys function and hepatic abscess. ${ }^{14}$ It causes septicemia of digestive origin that can cross the placenta resulting in chorioameniotitis maternal fetal infection with $S$. typhi can lead to miscarriage fetal death, neonatal infection as well as diverse maternal complication. ${ }^{15}$ Hydatid disease of the liver complicated by Salmonellosis ${ }^{16}$ and Cerebral $S$. typhi muriumabscessina patient with stroke have been reported.$^{17} S$. typhi infection in children younger than five years of age has also been done. ${ }^{18}$ The complications of typhoid fever in children include generalized edema. ${ }^{19}$

The samples used to detect salmonella organism are blood, urine, stool and bone marrow. The gold standard of bacteriological confirmation of typhoid fever is the bone marrow culture, which is positive in 85 to $96 \%$ of cases, even when the patients have received antibiotics. Typhoid fever had been diagnosed earlier by 
blood culture and widal test. Widal test remained the common test for typhoid detection. Serological diagnosis of typhoid infection has been also reported.$^{20}$ Since 1990 , multidrug resistant variety of typhoid fever had been prevalent in many parts of India, caused by S. typhi resistant to Chloramphenicol, Ampicilin Trimethoprim and Sulphamethoxazole. ${ }^{21}$

The Centre for Disease Control and Prevention has identified immunization as the most important public health advance of the $20^{\text {th }}$ century. Vaccination is an easy and highly effective way to keep travelers healthy. ${ }^{22}$ Despite effective treatment of typhoid fever, the increasing report of MDRST make it necessary for vaccine to be used as public health tool in developing countries. ${ }^{23}$ Considerable progress has been made in the last decade to develop vaccines against the enteric infections which are of greatest public health importance. Two vaccines against typhoid fever (Parenteral Vipolysaccharide and oral Ty21a) have been licensed in many countries. ${ }^{20} \mathrm{~A}$ new typhoid vaccine composed of the Vi capsular polysaccharide has been reported. ${ }^{24}$

\section{Material and methods}

\section{Area selection}

District Swat was selected for research on the prevalence of Typhoid because no such work was done in this area. For this purpose the data were collected from Dr. Khan Shahed (D. K. S. M) Hospital Matta, Dispensary of Gowlari and Parrow District Swat. In the Dispensary of Golari and Parrow no proper diagnosed infected patients were found. So, for the further study, the data were analyzed for those patients who visited the DKSM Hospital for diagnosis during the year of 2012. The D. K. S. M Hospital is located at Mattabazaar Matta Swat. It is having well-furnished wards, well qualified staff, doctors and well equipped laboratories for diagnosis of typhoid. Prior permission was taken from the hospital administration to have an access to the clinical data. The OPD was used for primary data collection because it is accessible for most of the patients and most of the patients were diagnosed by the doctors in the Outpatient Department (OPD) and in patient Deportment (IPD). The data were collected in which different types of information of the patients were recorded and designed in such a manner that names, age, gender, marital status, monthly occurrence of the patients of typhoid were recorded for analysis.

\section{Data analysis}

The data of the year 2012 were collected from the D. K. S. M Hospital Matta, Dispensary of Parrow, \& Gwalerai Swat. The analysis of data was only done for the patients of Typhoid. The following parameters were analyzed in the data.

I. Age wise occurrence of typhoid: The total patients were divided into different groups based on the irages such as (0-15), (15-30), (30-45), (45-60), and (60+). The percent age were calculated for each group.

II. Gender wise occurrence of typhoid: The patients were divided into two groups based on the ir sexes, i. e. male and female. The percentage of male and female was calculated and for each group.

III. Marital status of typhoid fever patients: The calculation was also done for the marital status of the patient's i. e. married and unmarried. The percentage was sorted out for the se.
IV. Monthly occurrence of typhoid: The patients had different number and value in different month of the year. The table and figure was made for simplification of data to easily understand able.

V. Seasonal occurrence of typhoid: The occurrences of typhoid patient were different in the four season of the year 2012. For the proper understanding the raw data were converted to tabulated form and made table for four seasons of the year of 2012.

VI. Comparison of indoor \& outdoor patient at D. K. S. M hospital matta: Comparison of indoor and outdoor patient was determined. That the outdoor patient was greater or indoor patient in D. K. S. M Hospital Matta Swat, The percentage was sorted out for the se.

VII. Age and gender wise occurrence of typhoid: The collected data were analyzed for the age and gender wise infection of salmonella typhi. The table and figure were drawn for the presentation of infected peoples. The data were analyzed statistically for each parameter. The results obtained have been presented in the form of tables and graphs using online statistical software, prism and demo.

\section{Results}

The present study was conducted to evaluate the occurrence of typhoid in District Swat. The recorded clinical data were collected from Dr. Khan Shahed Memorial Hospital (DKSMH) Matta Swat, Dispensary of Parrow and Gowaleri and analyzed for different parameters. In the dispensary of parrow and Gowlari 85 and 97 suspected patients were present respectfully but no infected patients were found. Infected patients were absent because there is lake of suitable Health care facility like clinical laboratory. Forth is reason, most of the peoples went to DKSM Hospital for proper diagnosis. So, for the further study the patients of DKSM Hospital were proposed. Only those patients were considered in the present study for further analysis who visited Dr. Khan Shaheed Hospital Matta and were positive diagnosed for Typhoid. The results were recorded and have been presented as follow;

\section{Occurrence of typhoid in district swat}

The collected data was only confined to the year of 2012. In year of 2012totalof 2552 people visited the DKSM Hospital for the diagnosis of Typhoid. Out of 2552, 346 were diagnosed positive for Typhoid. Only the typhoid patients were considered for further study. The occurring ratio of typhoid patients was $13.56 \%$ in District Swat during the year of 2012. The results were analyzed for following parameters.

I. Age wise occurrence of typhoid: During the study work, 2552 people visited the DKSM. Hospital Matta for the diagnosis of typhoid. Among these, only 346 (13.56\% patients were diagnosed positive for typhoid. The patients were divided into different age groups on the basis of their ages. Out of $346(13.56 \%)$ patients, there were $2(0.58 \%)$ patients in the age group of $0-15$ year, $15(4.34 \%)$ patients in the age group of $15-30$ years, $59(17.05 \%)$ patients in the age group of $30-45$ years, $222(64.16 \%)$ patients in the age group of $45-60$ years, $48(13.88 \%)$ patients in the age group of +60 years as shown in the Table $1 \&$ Figure 1.

II. Gender wise occurrence of typhoid: 346 patients were diagnosed positive for typhoid in the total of 2552 at DKSM 
Hospital Matta swat. Out of 346patients, $162(46.82 \%)$ patients were male and $184(53.18 \%)$ patients were female (Figure 2). The results showed high rate of occurrence in female $(53.18 \%)$ than male (46.82\%) (Table 2).

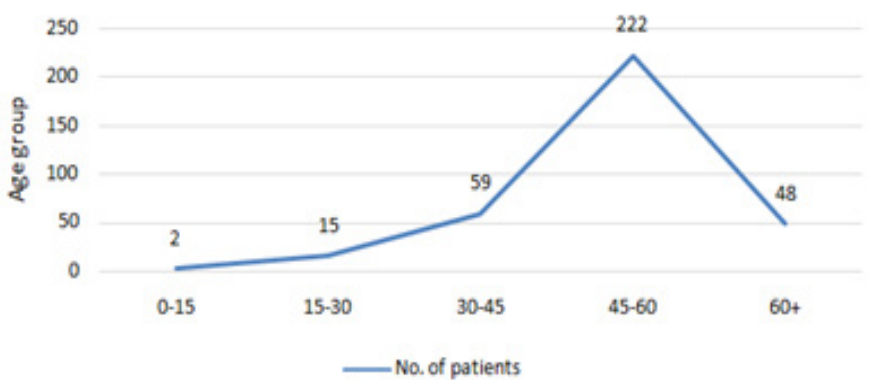

Figure I Age wise occurrence of Thyphoid $(n=346)$.

Table I Showing age wise occurrence of Typhoid

\begin{tabular}{lll}
\hline Age group & Number of patients & $\%$ Age \\
\hline 0 tol5 & 2 & $0.58 \%$ \\
15 to 30 & 15 & $4.34 \%$ \\
30 to 45 & 59 & $17.05 \%$ \\
45 to60 & 222 & $64.16 \%$ \\
60 & 48 & $13.88 \%$ \\
Total & 346 & $100 \%$ \\
\hline
\end{tabular}

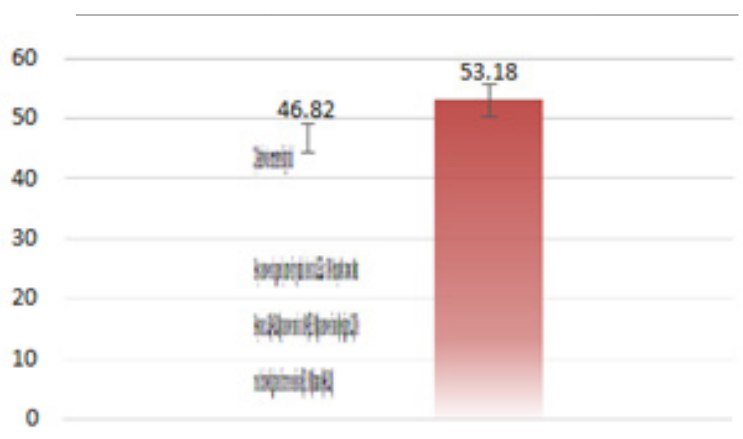

Percentage was calculated in total patients $(n=346)$

Male $m$ Female

Figure 2 Gender wise occurrence of Typhoid in Matta swat.

Table 2 Showing the gender wise prevalence of typhoid in the study area $(n=346)$

\begin{tabular}{lll}
\hline Gender & No. of +ve cases & Prevalence (\%) \\
\hline Male & 162 & $46.82 \%$ \\
Female & 184 & $53.18 \%$ \\
Total & 346 & $13.55 \%$ \\
\hline
\end{tabular}

III. Marital status of typhoid patients: In the analyzed data, 346patientswerepositivefor Typhoid. These patients were divided into two groups based on their marital status. Out of 346 patients, 272 (78.6\%) patients were married and 74 (21.4\%) patients were unmarried. It showed that Typhoid was high in married people as compared to unmarried (Figure 3).

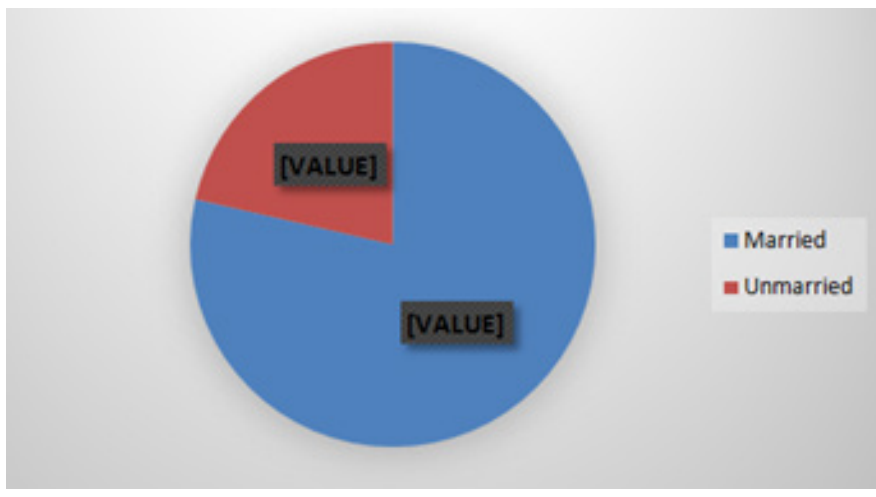

Figure 3 Marital status of Typhoid patients $(\mathrm{N}=346)$.

Table 3 Monthly occurrence of Typhoid

\begin{tabular}{lll}
\hline Month & No. of patient & Percentage (\%) \\
\hline January & 5 & $1.45 \%$ \\
February & 8 & $2.31 \%$ \\
March & 11 & $3.17 \%$ \\
April & 22 & $6.36 \%$ \\
May & 30 & $8.67 \%$ \\
June & 36 & $10.40 \%$ \\
July & 41 & $11.85 \%$ \\
August & 56 & $16.90 \%$ \\
September & 60 & $17.34 \%$ \\
October & 37 & $10.70 \%$ \\
November & 24 & $6.93 \%$ \\
December & 16 & $4.62 \%$ \\
\hline Total & 346 & $100 \%$ \\
\hline
\end{tabular}

IV. Monthly occurrence of typhoid: The re were 346 patient of Typhoid, out of these $5(1.45 \%)$ in January, $8(2.32 \%)$ in February, $11(93.17 \%)$ in March, $22(6.36 \%)$ in April, 30 (8. $67 \%$ ) in May, 36 (10. 40\%) June, 41 (11.85\%) July, 56 (16.9\%) in august, 60 (17.34\%) in September, $37(10.70 \%)$ in October, $24(6.93 \%)$ in November and $16(4.62 \%)$ in December. The results showed that the number of patients were greater in august, September and October, but gradually decrease from November to January (Table 3) \& (Figure 4).

V. Seasonal occurrence of typhoid patients: Prevalence of Typhoid was high in summer season, i. e. $193(55.79 \%)$, inspiring the number were decrease $63(18.20 \%)$, in the autumn the occurrence of Typhoid patient were decrease further 61 $(17.63 \%)$, but in the winter the recorded cases were less from all the seasons $29(8.38 \%)$. The results showed that the salmonella infected people was more in summer. The percentage was calculated in the total of 346 (Table 4) \& (Figure 5).

VI. Comparison of indoor and outdoor patient of typhoid at D. K. S. H Mata: There were 346 patients of Typhoid visited to D. K. S. H Matta out of the $\mathrm{m} 240$ (69.37\%) was outdoor and $106(30.35 \%)$ was admitted, no death occurs in admitted patient during the year 2012. The result showed that the infection of 
salmonella was severe in the indoor patient and outdoor were not severe but greater in number. The percent age was calculated in total of 346 (Table 5).

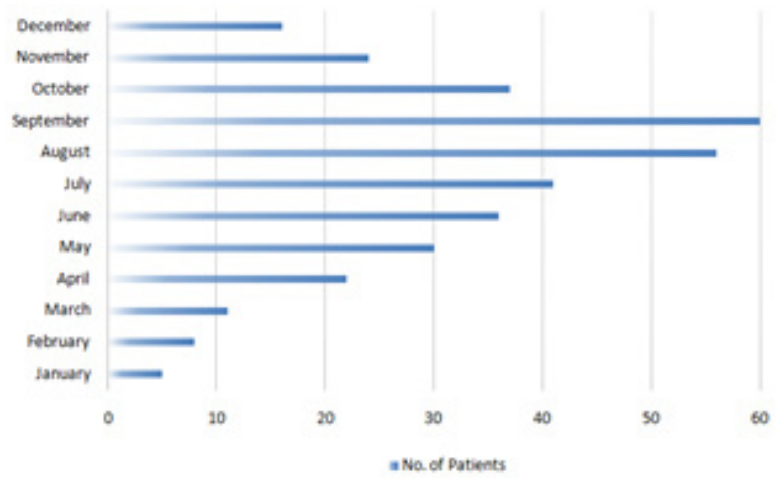

Figure 4 Monthly occurrence of Typhoid.

Table 4 Showing seasonal occurrence of Typhoid

\begin{tabular}{lll}
\hline Seasons & No. of patients & Percentage (\%) \\
\hline Spring & 63 & $18.20 \%$ \\
Summer & 193 & $55.79 \%$ \\
Autumn & 61 & $17.63 \%$ \\
Winter & 29 & $8.38 \%$ \\
\hline Total & 346 & $100 \%$ \\
\hline
\end{tabular}

Percentage was calculated in total patients $(n=346)$

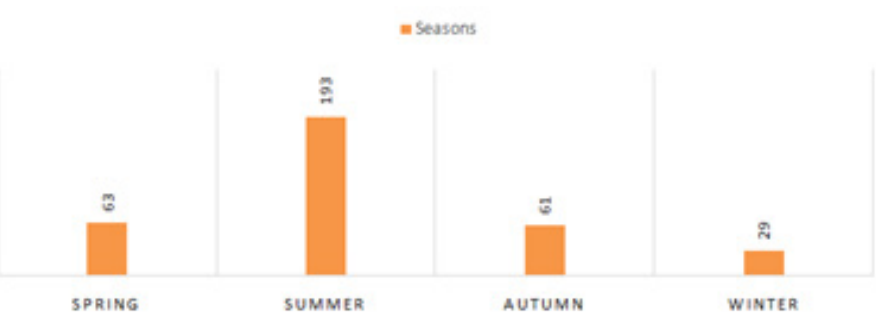

Figure 5 Showing seasonal occurrence of Typhoid.

Table 5 Comparison of indoor and outdoor patients

\begin{tabular}{lll}
\hline Patient type & No. of Patient & Percentage (\%) \\
\hline In door & 106 & $30.35 \%$ \\
Out door & 240 & $69.37 \%$ \\
\hline Total & 346 & $100 \%$ \\
\hline
\end{tabular}

Percentage was calculated in total patients $(n=346)$

VII. Age groups and gender wise occurrence of typhoid: There were 346 patients, out of these, $2(0.58 \%)$ were in the age group of $0-15$ years in which no $(0)$ were male $2(0.58 \%)$ were female. $15(4.34 \%)$ patients were in the age group of $15-30$ years, out of which, $5(1.45 \%)$ were male and $10(2.9 \%)$ were female. 59 $(17.05 \%)$ patients were in the age group of $30-45$ years, out of $59(17.05 \%)$ patients, $29(8.38 \%)$ were male and $30(8.7 \%)$ were female. In the age group of 45-60 years there were $222(64.16 \%)$ patients, out of these, $100(28.90 \%)$ were male and $122(35.26 \%)$ patients were female. In the age group of +60 there were 48 $(13.88 \%)$ patients, out of these $28(8.09 \%)$ patients were male and $20(5.8 \%)$ patients were female. The results showed that the adults were highly affected with Typhoid. Results also showed that the occurrence rate of Typhoid was high in female than male as shown in Table 6.

Table 6 Age and gender wise occurrence of Typhoid

\begin{tabular}{lllllll}
\hline $\begin{array}{l}\text { Age } \\
\text { group }\end{array}$ & $\begin{array}{l}\text { Number of } \\
\text { patients }\end{array}$ & Percentage (\%) & $\begin{array}{l}\text { Number of } \\
\text { male }\end{array}$ & Percentage (\%) & $\begin{array}{l}\text { Number of } \\
\text { female }\end{array}$ & Percentage (\%) \\
\hline $0-15$ & 2 & $0.58 \%$ & 0 & $0 \%$ & 2 & $2.58 \%$ \\
$15-30$ & 15 & $4.34 \%$ & 5 & $1.45 \%$ & 10 & $2.90 \%$ \\
$30-45$ & 59 & $17.05 \%$ & 29 & $8.38 \%$ & 30 & $8.70 \%$ \\
$45-60$ & 222 & $64.16 \%$ & 100 & $28.90 \%$ & 122 & $35.26 \%$ \\
$60+$ & 48 & $13.88 \%$ & 28 & $8.09 \%$ & 20 & $5.80 \%$ \\
\hline Total & 346 & $100 \%$ & 162 & $46.82 \%$ & 184 & $54.24 \%$ \\
\hline
\end{tabular}

Percentage was calculated in total patients $(n=346)$

\section{Discussion}

Typhoid fever is one of the most common infectious disease in developing countries including Pakistan. The disease is present especially in areas where healthcare facilities are limited and peoples are illiterate, living in unhygienic surroundings, drink raw-water from tube-wells and not habitual of hand -washing after toilet by soap. Symptoms and signs of the disease are non-specific and laboratory tests are essential for diagnosis. Early and reliable diagnosis of the disease is not only important in relieving patients suffering, but also essarytoavoidinglifethreateningcomplicationsincludingperforationof the intestine. ${ }^{25}$ The present study was conducted to evaluate the occurrence of typhoid in District Swat. The recorded clinical data was collected from Dr, Khan Shaheed Memorial Hospital (DKSM) Matta Swat; Dispensary of Parrow and Gowaleri and analyzed for different parameters. In the dispensary of parrow and Gowlari 85 and 97 suspected patients were present respectfully but no infected patients were found. Infected patients were absent because there is lake of suitable Health care facility like clinical laboratory. For this reason, most of the people swent to DKSM Hospital for proper 
diagnosis. So, for the further study the patients of DKSM Hospital were proposed. Only those patients were considered in the present study for further analysis who visited Dr, khan shahed Hospital Matta and were positive diagnosed for Typhoid. The results were recorded.

Jawad $\mathrm{K}$ et $a .^{26}$ studded 235 Typhoid patients in which the frequency distribution of typhoid fever cases per age groups of patients ranged from less than first year to sixteen years old, the agegroup $(>12-14$ years old)of patient shows the highest frequency $(24.2 \%)$ with typhoid fever ed. In the current study the age group 45 60 shows the highest frequency $222(64.16 \%)$. According to Rahman AKMM et al. ${ }^{27}$ out of 84 , prevalence of Typhoid fever was highest $54(56.25 \%)$ among the school age (5-10year) patients followed by adolescents. But in the present study total was 336 Typhoid patients in which the prevalence was highest $222(64.16 \%)$ in young peoples, the age group of 45-60. The finding of Rahman AKMM et al. ${ }^{27}$ is not in correlation. This may be since in this area the working age group 4560 who are exposed to infection early in the community. During the study work, 2552 people visited the DKSM. Hospital Matta for the diagnosis of typhoid. Among these, only 346 (13.56\%) patients were diagnosed positive for typhoid. The patients were divided into different age groups based on their ages. Out of $346(13.56 \%)$ patients, there were $2(0.58 \%)$ patients in the age group of $0-15$ year, $15(4.34 \%)$ patients in the age group of 15-30years, $59(17.05 \%)$ patients in the age group of 30-45years, $222(64.16 \%)$ patients in the age group of $45-60$ years, $48(13.88 \%)$ patients in the age group of +60 years.

The research work of Anand PK \& Ramakrishnan $\mathrm{R}^{28}$ evaluated that the attack rate of disease was 104 cases per 1000 population i.e. 95.45 and 114 cases per 1000 population in male and female respectively. In present study, $46.82 \%$ male and $53.18 \%$ female were typhoid patients. The percentage of typhoid in female was greater than male. Therefore, the result of current study is in favor with the study of Anand PK \& Ramakrishnan $\mathrm{R}^{28}$. In the current work 346 patients were in consideration in which $162(46.82 \%)$ patients were male and 184 $(53.18 \%)$ patients were female as shown. The results showed high rate of occurrence in female $(53.18 \%)$ than male $(46.82 \%)$. Waris et al. ${ }^{29}$ studded 97 Typhoid patients. Among the m50 (51\%) were married and $47(48.5 \%)$ unmarried. In the present research, the frequency of married patients was higher than unmarried. So, present research work is in agreement with the work of Waris Qidwai et al. ${ }^{29}$ The reason may be that, the overall number of married people sis greater than single. In the analyzed data, 346 patients were positive for Typhoid. These patients were divided into two groups on the basis of their marital status. Of these $272(78.6 \%)$ patients were married and $74(21.4 \%)$ patients were unmarried. It showed that Typhoid was high in married people as compared to unmarried.

The incidence of typhoid fever in Matta Swat, as seen retrospectively for the year2012inthe Dr. Khan shaheed memorial hospital (DKSMH) records, showed monthly and seasonal variations. The peak incidence of typhoid infection in Matta Swat coincided with the beginning of the rainy season which is June-September each year. The result showed that $56.49 \%$ of all typhoid cases occurred now. This finding is most likely associated with increased microbial (bacterial) contamination of flowing surface water at this period of the year. Similarly, the finding that typhoid fever occurs twice as often in the rainy season sin the dry season can be linked to the transmission of Salmonella typhi through water contamination during the rainy season. Poor sewage disposal contributes to these findings. In most parts of Swat, sewage disposalisin discriminate. Sewage is usually washed into water sources mainly the surrounding streams and rivers.
It is also likely that the perennial water supply problem evident in most parts of Swat explains the consistent incidence of typhoid fever. In other studies, similar assertions have been made, for example; In Lagos, Nigeria, three peak incidences of typhoid infection in April, July and November had been reported. ${ }^{30}$ Similarly, Ozumba et al. ${ }^{31}$ reported a definite seasonal incidence with two peaks coinciding with two rainy seasons in Ghana.

Shah GJ \& Poudel $\mathrm{TP}^{32}$ reported that the frequency of typhoid fever was high in summer season (May, June, and July)and in present study the number of typhoid patients was also high $(55.79 \%)$ in summer. Therefore, the current work is in correlation with the work of Shah GJ \& Poudel TP. ${ }^{33}$ The reason may be the more rain fall in the summer that may increase the growth rate of Salmonella typhi. There were 346 patients, out of these, $2(0.58 \%)$ were in the age group of $0-15$ years in which the infection among male and females $(0 \%$ and $0.58 \%) .15(4.34 \%)$ patients were in the age group of $15-30$ years, out of which, $5(1.45 \%)$ were male and $10(2.9 \%)$ were female. 59 $(17.05 \%)$ patients were in the age group of 30-45 years, out of 59 $(17.05 \%)$ patients, $29(8.38 \%)$ were male and $30(8.7 \%)$ were female. In the age group of $45-60$ years there were $222(64.16 \%)$ patients, out of these, $100(28.90 \%)$ were male and $122(35.26 \%)$ patients were female. In the age group of +60 there were $48(13.88 \%)$ patients, out of these $28(8.09 \%)$ patients were male and $20(5.8 \%)$ patients were female. Sharma et al. ${ }^{33}$ evaluated 112 patients of Typhoid, 80 $(71.43 \%)$ were below the age group 30 year, of which $58(51.78 \%)$ was male while $22(19.64 \%)$ was female and the remaining 32 (28.57) were above from age 30 year, that showed same percentage of male \& female. The present study the number was more in the age group 4560 in which $28.90 \%$ was male \& $35.26 \%$ was female. The finding of Sharma et al. ${ }^{33}$ contrasts with the present study. The reason may be that Sharma et al. ${ }^{33}$ was studied the general population and the present study was conducted on only Typhoid Patients.

\section{Conclusion}

The above study shows that prevalence of enteric fever was found to be high and most commonly observed in young productive age group 45-60 females followed by 30-45 years age group. Enteric fever is commonest health problem in developing country like Pakistan. The occurrence of typhoid was high in summer season due to the high rainfall. Where water supplies and sanitation are sub-standard. Large numbers of bacterial organisms Salmonella species are excreted in urine and faecal specimens during the diseases. An infection is by ingestion of the Salmonella species in contaminated food or water or directly from faeces and contaminated fingers. Prevention of enteric fever is mainly by personal and domestic hygiene. The provision of clean piped water supplies and the safe disposal of faeces will be implementing as soon as possible in Swat valley. ${ }^{34}$

\section{Recommendation}

There is lake of knowledge about this disease in the peoples of Matta Swat therefore it is recommended that:

I. Government Public Health Department should have arranged such programs that give awareness to people about this lifethreatening disease.

II. Peoples should be properly educated, Electronic as well as printed media be used for this purpose. Itisal so recommended that the peoples should be used proper hygiene and was hinghands after Toilet attendance. 
III. Moreover, further research should be done on high population to sort out the other risk factors.

IV. Government should provide mobile teams to the infected areas so that proper checkup of infected patient becomes possible.

V. Most of the people in the study area are poor so it is recommended that government should provide free medical facilities so that proper treatment of the disease becomes possible.

\section{Acknowledgments}

We are very thankful to Pathology department staff and laboratory technicians of Dr. Khan Memorial Hospital (DKMH) and Local health care centers of Matta Swat, for their assistance in collecting data.

\section{Conflicts of interest}

The authors have declared that no competing interests exist.

\section{Author Contributions}

Conceived and designed the experiments: SA, AAK

Performed the experiments: SA, AAK

Analyzed the data: AAK, IH, AK

Wrote the paper: AK, SK

\section{References}

1. Newell DG, Koopmans M, Verhoef L, et al. Food-borne diseasesthe challenges of 20years agostillpersist while new ones continue to emerge. International Journal of Food Microbiology. 2010;139(Suppl 1):S3-S15.

2. Montville TJ, Matthews KR. Food microbiology: An introduction. $\left(2^{\text {nd }}\right.$ edn), ASM Press, Washington, USA, 2008.

3. Pui CF, Wong WC, Chai LC, et al. Simultaneous detection of Salmonella spp., Salmonella Typhi and Salmonella Typhimurium in sliced fruits using multiplex PCR. Food Control. 2011;22:337-342.

4. Crump JA, Luby SP, Mintz ED The global burden of typhoid fever Bulletin of the WHO. 2004;82(5):346-53.

5. Lesser CF, Miller SI Salmonellosis. In: Braunwald E et al, editor. Harrison's Principles of Internal Medicine., (15 th $\mathrm{edn})$, McGraw-Hill, New York, USA, 2001; p. 971-973.

6. Corales R. Typhoid fever.2004

7. Pithie AD, Malin AS, Robertson VJ. Salmonella and Shigella bacteraemia in Zimbabwe. Cent Afr J Med. 1993;39(6): 110-112.

8. Zhang S, Kingsley R, Santos RL et al. Molecular Pathogenesity of Salmonella enterica serotype Typhimurium-induced diarrhea. Infection and Immunity. 2003;71(1):1-12.

9. Leniaud P, Vitris M, Bernard A, et al. Typhoid fever in a resuscitation department. Apropos of 42 cases. Med Trop (Mars). 1984;44(2):121126.

10. Rahman GA, Abubakar AM, Johnson AW, et al. Typhoid ileal perforationin Nigerian children: an analysis of 106 operative cases. Pediatr Surg Int. 2001;17(8):628-630.

11. Rombola F, Bertuccio SN. Typhoid fever and acute pancreatitis: two cases. Infez Med. 2007;15(1):63-65.

12. Nasir AA, Adeniran JO, Abdur-Rahman LO, et al. Typhoid intestinal disease: 32 perforations in 1 patient. Niger Postgrad Med J. 2008;15(1):55-57.
13. Singh NP, Manchanda V, Gromber S, et al. Typhoidal focal suppurative lymphatic abscess. Ann Trop Paediatr. 2002;22(2):183-186.

14. Soni PN, Hoosen AA, Pillay DG. Hepatic abscess caused by Salmonella typhi. A case report and review of the literature. Dig Dis Sci. 1994;39(8):1694-1696.

15. Carles G, Montoya Y, Seve B, et al. Typhoid fever and pregnancy. $J$ Gynecol Obstet Biol Reprod (Paris). 2002;31(5):495-499.

16. Sadhu D, Moses BV, John R, et al. Hydatid disease of the liver complicated by salmonellosis. Trans $R$ Soc Trop Med Hyg. 1993;87(6):674-675

17. Arentoft H, Schonhcyder H, Schonemann NK. Cerebral Salmonella typhimurium abscess in a patient with a stroke. Infection. 1993;21(4):251-253.

18. Mahle WT, Levine MM. Salmonella typhi infection in children younger than five years of age. Pediatr Infect Dis J. 1993;12(8):627-631.

19. Madariaga M, Vildosola H, Lianez JC, et al. Complication of typhoid fever in children: an asarca. A case report and review of the literature. Rev Gastroenterol Peru. 1995;15(1):79-86.

20. Obgol'ts AA, Klishevich VP, Televnaia LG. Serological diagnosis of typhoid infection. Microbiol Epidemiol Immunobiol. 1985;6:103-106.

21. John TJ Emerging and re-emerging bacterial pathogens in India. Indian J Med Res. 1996;103:4-18.

22. Sturchler MP, Steffen R. Vaccinations for overseas travelers-new evidence and recommendations. Ther Umsch. 2001;58(6):362-366.

23. Mastroeni P, Menager N. Development of acquired immunity to Salmonella. Med Microbiol. 2003:52:453-459.

24. Plotkin SA, Bouveret-Le Cam N. A new typhoid vaccine composed of the Vi capsular polysaccharide. 1995;155(21):2293-2299.

25. Sultana S. Comparison of different test methods including polymerase chain reaction for early and reliable diagnosis of typhoid fever. Mymensingh medical college, Bangladash, 2012; p. 2-169.

26. Jawad K, AL-Khafaji T, FAL-Yasari H, et al. Prevalence of Typhoid Fever among Pediatric Patientsat AL-Musaib District. Medical Journal of Babylon. 2006;2:75-80.

27. Rahaman AKMM, Ahmad M, Begum RS. Prevalence of Typhoid fever among the children inasemi urban area of Bangladesh. J Dhaka Med Coll. 2011;20:38-43.

28. Anand, PK, Ramakrishnan R. Investigation of the outbreak of typhoid in a village of Thar Desert Rajasthan, India. Indian $J$ Med Res. 2010;131:799-803.

29. Qidwai W, Sohail Ali S, Ayub S, et al. Knowledge, attitude and practice regarding immunization among family practice patients. JDUHS 2007;1(1):15-19.

30. Onabowale O, Ogunbiyi TA. Typhoid enteritisin Lagos, Nigeria Nigerian Medical Journal. 1996;6(4):45-47.

31. Ozumba NA, Ozumba UC, Obionu C. Typhoid fever epidemic in Nigeria. Journal of College of Medicine. 1997;2(2):31-35.

32. Shah GJ, Poudel TP. A Study of Typhoid Fever in Bheri Zonal Hospital and Nepalgunj Medical College Teaching Hospital, Banke, Nepal. JHAS. 2013;3(1):31-34.

33. Sharma N, Koju R, Karmacharya B, et al.Typhoid fever in Dhulikhel hospital, Nepal. Kathm and University Medical Journal. 2003;7(2,3):188-192.

34. Bouchrif B, Paglietti B, Murgia M, et al. Prevalence and antibioticresistance of Salmonella isolated from food in Morocco. Journal of Infect Developing Countries. 2009;3(1):35-40. 